\title{
Late gadolinium enhancement patterns on cardiac magnetic resonance images in heart transplant patients
}

\author{
Patrizia Pedrotti*1, Santo Dellegrottaglie ${ }^{2}$, Stefano Pedretti ${ }^{1}$, Claudia Vittori ${ }^{1}$, \\ Manlio Cipriani ${ }^{1}$, Maria Frigerio ${ }^{1}$, Pasquale Perrone-Filardi ${ }^{2}$, \\ Massimo Chiariello ${ }^{2}$ and Alberto Roghi ${ }^{1}$
}

Address: ${ }^{1}$ Niguarda-Ca' Granda Hospital, Milan, Italy and ${ }^{2}$ Federico II University, Naples, Italy

* Corresponding author

from 13th Annual SCMR Scientific Sessions

Phoenix, AZ, USA. 21 -24 January 2010

Published: 21 January 2010

Journal of Cardiovascular Magnetic Resonance 20 I0, I2(Suppl I):O52 doi:I0.I I86/I532-429X-I2-SI-O52

This abstract is available from: http://jcmr-online.com/content/I2/SI/O52

(c) 2010 Pedrotti et al; licensee BioMed Central Ltd.

\section{Introduction}

Non-invasive monitoring of patients with heart transplant (HTX) is still unsatisfactory. Cardiac magnetic resonance (CMR) has emerged as a useful modality for accurately recognizing myocardial areas with late gadolinium enhancement (LGE) as an expression of altered tissue composition. Limited information are currently available about the presence and significance of myocardial LGE in HTX patients.

\section{Purpose}

To assess the prevalence and distribution of myocardial LGE on CMR images in HTX patients.

\section{Methods}

The study population included a group of 22 HTX patients (mean age, $51.0 \pm 16.5$ years; mean ischemia time of HTX, $160.0 \pm 47.4 \mathrm{~min}$ ) with $>1$ year of follow-up. Routine endomyocardial biopsies have been performed during follow-up in all patients based on a standardized schedule. Previous significant HTX rejection was documented in 7 patients. Patients with clinical and instrumental evidence of myocardial ischemia underwent invasive angiography to exclude transplant coronary artery disease (TCAD). Manifest TCAD was described in 8 patients. CMR exams were performed on a $1.5 \mathrm{~T}$ scanner. The study protocol included the acquisition of steady-state free precession cines in the standard planes covering the left ventricle (LV) and right ventricle (RV), followed by the acquisition of LGE segmented inversion-recovery gradient echo images in matching planes (starting $10 \mathrm{~min}$ after i.v. injection of gadolinium-DTPA, $0.15 \mathrm{mmol} / \mathrm{kg}$ ). LGE extension was calculated by planimetry in all short-axis slices and the total volume of LGE was expressed as a percentage of total myocardium (LGE\%).

\section{Results}

Areas of myocardial LGE were detected in 18 (82\%) patients. LGE with a typical ischemic-related pattern was observed in 4 patients (TCAD was demonstrated in all of them by angiography), while the remaining patients ( $\mathrm{n}=$ 14) presented with non ischemic-related patterns [frequently involving the interventricular septal junctions ( $\mathrm{n}$ $=5$ ) or the entire $L V$ with a diffuse infiltrative pattern ( $n=$ 5)]. In addition, 7 patients presented LGE also involving the RV myocardium. LGE\% showed a significant inverse correlation with LV ejection fraction $(\mathrm{r}=-0.66, \mathrm{p}=0.014)$ and RV ejection fraction $(\mathrm{r}=-0.64, \mathrm{p}=0.018)$. A multivariate analysis including age, ischemia time of HTX, HTXCMR time-interval, TCAD, previous rejections, selected the ischemia time of HTX as the only significant predictor of LGE\% (beta $=1.10, \mathrm{p}<0.05)$.

\section{Conclusion}

At a late post-HTX evaluation by CMR, myocardial LGE is highly prevalent and is more frequently observed with non ischemic-related patterns of distribution. The ischemia time of HTX was a significant predictor of LGE 
extension and this correlates with the ventricular systolic function.

Publish with Bio Med Central and every scientist can read your work free of charge

"BioMed Central will be the most significant development for disseminating the results of biomedical research in our lifetime. " Sir Paul Nurse, Cancer Research UK

Your research papers will be:

- available free of charge to the entire biomedical community

- peer reviewed and published immediately upon acceptance

- cited in PubMed and archived on PubMed Central

- yours - you keep the copyright 